\title{
The impact of fecal and urinary incontinence on quality of life 6 months after childbirth
}

\author{
Victoria L. Handa, MD, Halina M. Zyczynski, MD, Kathryn L. Burgio, PhD, Mary Pat \\ Fitzgerald, MD, Diane Borello-France, PT, PhD, Nancy K. Janz, PhD, Paul M. Fine, MD, \\ William Whitehead, PhD, Morton B. Brown, PhD, and Anne M. Weber, MD, MS for the Pelvic \\ Floor Disorders Network \\ Johns Hopkins University, Baltimore, MD (Dr Handa); University of Pittsburgh, Pittsburgh, PA (Dr \\ Zyczynski); University of Alabama, Birmingham, AL (Dr Burgio); Birmingham VA Medical Center, \\ Birmingham, AL (Dr Burgio); Loyola University, Chicago, IL (Dr Fitzgerald); Duquesne University, \\ Pittsburgh, PA (Dr Borello-France); University of Michigan, Ann Arbor, MI (Drs Janz and Brown); \\ Baylor College of Medicine, Houston, TX (Dr Fine); University of North Carolina, Chapel Hill, NC \\ (Dr Whitehead); and the National Institute of Child Health and Human Development, National \\ Institutes of Health (Dr Weber)
}

\section{Abstract}

Objective-The objective of the study was to investigate the impact of postpartum fecal incontinence (FI) and urinary incontinence (UI) on quality of life (QOL).

\begin{abstract}
Study Design-Seven hundred fifty-nine primiparous women in the Childbirth and Pelvic Symptoms study were interviewed 6 months postpartum. FI and UI were assessed with validated questionnaires. We measured QOL with SF-12 summary scores, health utility index score (a measure of self-rated overall health), and the modified Manchester Health Questionnaire.
\end{abstract}

Results-Women with FI had worse self-rated health utility index scores $(85.1 \pm 9.8$ vs $88.0 \pm$ 11.6, $P=.02$ ) and Medical Outcomes Study Short Form Health Survey (SF-12) mental summary scores $(46.8 \pm 9.2$ vs $51.1 \pm 8.7, P<.0001)$ than women without FI or flatal incontinence. Women with UI had worse SF-12 mental summary scores $(48.3 \pm 9.8$ vs $51.6 \pm 7.8, P<.01)$ and self-rated health utility index scores $(84.1 \pm 12.5$ vs $88.7 \pm 10.1, P<.01)$ than women without UI. Women with both FI and UI had the lowest SF-12 mental summary scores (44.5 \pm 9.0$)$.

Conclusion-Six months after delivery, women experiencing FI or UI reported negative effects on health-related QOL. FI and UI together have a greater impact than either condition alone.

\section{Keywords}

childbirth; fecal incontinence; quality of life; urinary incontinence

\begin{abstract}
In studies of fecal incontinence (FI) and urinary incontinence (UI) during the postpartum period, UI is reported by $10-50 \%$ of women, ${ }^{1-6}$ whereas FI is present in up to $25 \% .2,3,7$ The Pelvic Floor Disorders Network (PFDN) has previously published findings of the Childbirth and Pelvic Symptoms (CAPS) study, ${ }^{8}$ which examined the prevalence of FI and UI in 3 cohorts of primiparous women. FI was more prevalent (17.0\%) in women who delivered vaginally with recognized anal sphincter tears, compared with women who delivered
\end{abstract}

(C) 2007 Mosby, Inc. All rights reserved.

Presented at the 33rd Annual Scientific Meeting of the Society of Gynecologic Surgeons, Orlando, FL, April 12-14, 2007.

Reprints not available from the authors. 
vaginally without recognized anal sphincter tears $(8.2 \%)$ and women who delivered by cesarean prior to labor (7.6\%). UI was reported by $31.2 \%$ of participants and did not differ significantly by group.

In population-based studies, FI affects $2-12 \%$ of community-dwelling adults 9,10 and is associated with significant adverse impact on quality of life (QOL). ${ }^{9}$ Although several case series report the impact of postpartum UI on QOL, ${ }^{3,4,6}$ data are very limited on the impact of FI on QOL in the postpartum period. In a Canadian study, ${ }^{3}$ FI was present in $20.6 \%$ of 1305 primiparous women 6 months postpartum, and QOL varied significantly with the severity of both FI and UI.

The objective of this study was to examine the impact of postpartum FI and UI, alone and in combination, on health-related QOL in a cohort of primiparous American women.

\section{Materials and Methods}

\section{Participants and recruitment}

This study was conducted by the PFDN and sponsored by the National Institute of Child Health and Human Development. Data were obtained from women enrolled in the CAPS study ${ }^{8}$ which sought to estimate the prevalence of postpartum FI and UI in 3 cohorts of primiparous women: those with third- or fourth-degree anal sphincter tears that were clinically recognized and repaired at the time of delivery; women who delivered vaginally without clinically recognized anal sphincter tears; and those who underwent cesarean delivery without labor. Details of the CAPS study methodology and description of the study population are described elsewhere. ${ }^{8}$ Data from 759 women who participated in 6 month postpartum telephone interviews are included in this analysis.

Primiparous women were eligible for the CAPS study if they delivered a single child at gestation of 37 weeks or longer. Women with inflammatory bowel disease (ulcerative colitis or Crohn's disease), self-reported prepregnancy FI, a history of anorectal surgery, or neurological conditions predisposing to UI or FI were excluded from participation.

Institutional review board approval was obtained by each clinical site and the data coordinating center prior to subject recruitment. All participants provided written informed consent.

\section{Procedures}

At 6 months postpartum, research coordinators telephoned and interviewed participants using validated questionnaires to collect data regarding urinary and bowel symptoms, QOL, and sexual function. Coordinators from each clinical site received training and certification in telephone interview procedures from the Quality of Life Telephone Interviewing Facility at the University of Michigan.

\section{Measures}

Fecal incontinence-FI was assessed with the Fecal Incontinence Severity Index (FISI) ${ }^{11}$ which determines the frequency of 4 symptoms (incontinence of gas, mucus, liquid stool, and solid stool) using the following response options: 2 or more times a day, once a day, 2 or more times a week, once a week, 1-3 times per month, or never. FI was defined as any involuntary leakage of mucus, liquid stool, or solid stool on the FISI. Subjects who indicated a positive response only for incontinence of gas on the FISI were considered to have incontinence of "flatus only" and not FI. The FISI score (range 0-61) was used as a measure of FI severity, with higher scores indicating higher FI severity. 
The symptom of fecal urgency was assessed by a single item ("How often do you have a strong desire to move your bowels, which makes you rush to the toilet?"). This item was considered affirmative if the woman gave a response of "sometimes," "often," or "always."

Urinary incontinence-UI symptoms were measured using the Medical, Epidemiological, and Social Aspects of Aging (MESA) Questionnaire, ${ }^{12}$ which includes 15 items, 9 for stress incontinence symptoms and 6 for urgency and urge incontinence. Response options are "never," "rarely," "sometimes," or "often." Presence of UI was defined by a response of "sometimes" or "often" to any of the MESA questions. Type of UI was defined as: "stress incontinence only," which was a positive ("sometimes" or "often") response to 1 or more of the 9 stress incontinence questions but none of the 6 urge or urge incontinence questions; "urge incontinence only," which was a positive response to 1 or more of the 6 urge or urge incontinence questions but none of the 9 stress incontinence questions; and "mixed incontinence," which was a positive response to at least 1 of the stress incontinence questions plus at least 1 of the urge or urge incontinence questions.

The Hunskaar score ${ }^{13}$ described UI severity as the product of the frequency and volume of incontinent episodes (range 0-12). Severity categories are: continent (0), slight (1-2), moderate (3-6), severe (7-9), and very severe (10-12).

Quality of Life-The SF-12 Health Survey assessed generic health-related QOL. ${ }^{14}$ The SF-12 has 2 summary scores, the Physical Component Summary (hereafter referred to as SF-12 physical summary) and the Mental Component Summary (SF-12 mental summary), which assess physical and mental functioning, respectively. Both of these scores have a range from 0 to 100 , with higher scores indicating better QOL. Subjects were asked the 1item Health Utility Index ${ }^{15}$ that measures overall health on a scale from 0 (death) to 100 (perfect health). The impact of FI symptoms on QOL was assessed with the Modified Manchester Health Questionnaire, ${ }^{16}$ which is based on the Manchester Health Questionnaire, ${ }^{17}$ a 31 -item condition-specific QOL instrument with 8 sub-scales. We focused on 2 parts of the Modified Manchester: the "severity" subscale score (range 0-100, with higher scores indicating worse symptoms) and a single item that assesses the impact of bowel symptoms on life ("not at all," "a little bit," "moderately," "quite a bit," or "extremely"). We considered a negative response to include responses of "not at all" or "a little bit" and positive response to include responses of "moderately," "quite a bit," or "extremely."

Sexual Function-We administered the Pelvic Organ Prolapse/Urinary Incontinence Sexual Function Questionnaire (PISQ-12) to sexually active women. ${ }^{18}$ This QOL instrument was added after the CAPS study was underway and was administered to 595 of the participants. The PISQ-12 measures sexual function for women with pelvic floor disorders. The score ranges from 0 to 48 , with higher scores indicating better sexual function.

\section{Analysis}

To examine the impact of FI on QOL, we created 3 groups for comparison: those with FI, those with flatal incontinence only, and those with no FI or flatal incontinence. Similarly, to examine impact of UI, we compared women with and without UI on each QOL measure. Mean scores for each QOL measure were first compared between the groups using a general linear model (analysis of variance); each analysis was performed first without adjustment and repeated with adjustment for site, race, and marital status. All statistical tests were 2 tailed using an alpha of 0.05 . Proportions were compared by a Mantel-Haenszel statistic $\chi^{2}$ test) both without adjustment and with adjustment for site, race, and marital status. When a statistically significant difference $(P<.05)$ was observed, we conducted unadjusted pair- 
wise comparisons between groups. To examine the impact of FI severity (FISI score) and UI severity (Hunskaar score) on QOL measures, Spearman nonparametric correlations were computed.

To estimate the independent effects of FI and UI on the QOL measures, a regression model was fitted to the QOL summary scores. The regression model included indicator variables for FI and UI and their interaction as well as terms for potential confounders (race, marital status, and predelivery body mass index $[\mathrm{BMI}])$.

\section{Results}

Of 921 women in the CAPS study, 759 (82\%) completed interviews at 6 months postpartum and form the sample for the present analysis. The demographic and obstetrical characteristics of the population have been previously described. ${ }^{8}$ Briefly, this analysis included data from 278 with a clinically apparent anal sphincter tear; 293 without recognized sphincter trauma, and 97 who delivered by cesarean section prior to labor. Women in this study had a mean age of 27.5 years; $71 \%$ were Caucasian; $33 \%$ were single or divorced; and $73 \%$ had some college or advanced education.

\section{Fecal incontinence and QOL}

FI was reported by 91 women (12.0\%) and flatus incontinence only was reported by 161 $(21.2 \%)$. The FI severity (FISI) score ranged from 0 to 43, with FISI score less than 4 in $75 \%$ of participants. Only 9 of the 91 participants with FI (9.9\%) reported more than 1-3 incontinent episodes per month (the lowest frequency category for any FI on the FISI).

The relationships between fecal and flatal incontinence and QOL measures are shown in Table 1. SF-12 mental summary and modified Manchester severity scores were worst in women with FI and best with no FI or flatal incontinence. Specifically, SF-12 mental summary scores were worst in women with FI, intermediate in those with flatal incontinence, and best in participants with neither FI nor flatal incontinence. SF-12 physical summary scores did not demonstrate significant differences between the groups.

Self-rated health utility index scores were lower (worse) for women with flatal incontinence or FI, compared with women with neither flatal incontinence nor FI. Participants with FI had the worst (highest) scores on the Manchester severity score. Considering the Manchester item that rates the impact of bowel symptoms on QOL, $18.7 \%$ of women with FI indicated a "moderate" to "extreme" impact, compared with only $2 \%$ of those without FI. No associations were found between fecal or flatal incontinence and resumption of sexual activity or the PISQ-12 score.

Several of the QOL measures were associated with the severity of FI (FISI score). Specifically, higher FISI scores were associated with lower (poorer) SF-12 mental summary scores and lower (poorer) self-rated health utility index scores (both $\mathrm{r}=-0.19 ; P<.001$ ) as well as higher (poorer) Manchester severity scores $(\mathrm{r}=0.37 ; P<.001)$. FI severity was not associated with significant changes in SF-12 physical summary scores $(\mathrm{r}=0.01 ; P=.85)$. FI frequency was associated with the impact of bowel symptoms: $15 \%$ (12 of 82) of women with FI 1-3 times per month reported moderate or higher impact, compared with 56\% (5 of 9) with more frequent fecal incontinence $(P=.01)$.

Women with FI were significantly more likely than women without FI to report fecal urgency (53 of 91 [58.2\%] vs 157 of 668 [23.5\%], $P<.0001$ ). Subjects with both fecal urgency and FI reported the worst (lowest) SF-12 mental summary scores $(45.7 \pm 8.8)$, the worst (highest) Manchester severity scores $(12.5 \pm 16.6)$ and were more likely to report 
moderate to extreme symptom impact from bowel symptoms (24.6\%). Comparing FI alone and fecal urgency alone, there were no differences between these groups in any QOL measure except the Manchester severity score (fecal urgency only $=3.6 \pm 8.3$; FI only $=9.6$ $\pm 17.7)$.

\section{Urinary incontinence and QOL}

To investigate the independent effect of UI on QOL, we considered QOL in women with and without UI, excluding women who also had FI. Compared with women with no UI or FI $(\mathrm{n}=479)$, women with UI $(\mathrm{n}=189)$ had worse SF-12 physical summary scores $(53.6 \pm 7.1$ vs $56.1 \pm 4.5, P<.01)$, SF-12 mental summary $(48.3 \pm 9.8$ vs $51.6 \pm 7.8, \mathrm{P}<.01)$, and health utility index scores $(84.1 \pm 12.5$ vs $88.7 \pm 10.1, P<.01)$.

Median Hunskaar severity score was 2 (range 0-12), representing "slight" UI. Three quarters of participants reported a score of 3 or below. We did not identify any significant correlations between UI severity and any of the QOL measures considered. Also, among women with UI, we found no significant differences in QOL outcomes between women with stress incontinence symptoms $(n=121)$ vs urge/mixed incontinence symptoms $(n=116)$.

\section{Dual incontinence and QOL}

Women with FI were significantly more likely than women without FI or flatus incontinence to report UI $(52.7 \%$ vs $24.4 \%, P<.01)$ (Table 2$)$. To explore the impact of dual incontinence (UI plus FI) on QOL, we compared 4 groups: women with neither FI nor UI, women with UI but no FI, women with FI but no UI, and women with both conditions (Table 3). Women with dual incontinence had the poorest SF-12 mental summary scores. Sexually active women with dual incontinence had lower PISQ-12 scores than women with neither condition. Manchester severity scores were not different between women with dual incontinence and women with FI only (ie, UI did not have a significant impact on Manchester severity scores).

In multivariable linear regression, controlling for education, marital status, race, and BMI, mean SF-12 mental summary scores were lower in women with FI by an average of 2.8 points and lower in women with UI by an average of 3.2 points. The mean health utility index score was lower in women with FI by an average of 0.7 points (not statistically significant) and lower in women with UI by an average of 3.9 points. Having both UI and FI did not change the impact of either condition on the SF-12 mental summary score or health utility index score.

\section{Comment}

Six months after delivery, FI and UI have important negative effects on health-related QOL. Among the young, primiparous women in this study, about 1 in $5(18.7 \%)$ with FI reported a "moderate" to "extreme" life impact (Manchester impact item), and women with FI had decreased quality of life, as evidenced by lower SF-12 mental summary scores and self-rated health utility index scores. Prior studies have shown decreased QOL among older women with FI, ${ }^{9,19,20}$ but these results suggest that FI symptoms are a burden, even for young, relatively healthy women who are with in 6 months of delivering a first child. Fecal urgency, which was reported by more than half of the women with FI, contributed to poorer QOL among women with FI. Flatal incontinence appears to have a less measurable influence on QOL than FI.

We observed a greater QOL impact with increasing FI severity. Specifically, increasing FISI score was associated with poorer (lower) SF-12 mental summary scores and self-rated health utility index scores. Also, women with more frequent FI episodes were more likely to report 
"moderate" to "extreme" life impact. It seems likely that the impact of FI on quality of life would be more dramatic in women with more severe and/or frequent FI, such as those seeking treatment. In this study, the magnitude of the QOL impact was greater for UI than FI. However, this finding was likely related to the low severity of FI in our sample and may not be generalizable to women presenting for treatment of UI and FI.

Although the presence of UI symptoms had a negative impact on health-related QOL, we were somewhat surprised to find that the severity and type of UI were not associated with QOL measures. Prior studies suggested a more significant negative impact for urge and mixed incontinence symptoms than for stress incontinence symptoms. ${ }^{21-23}$ QOL impact of UI may vary with age; in 1 study focusing on stress incontinence, younger women were more impaired than older women. ${ }^{22}$ The fact that our study focused on younger women might explain why stress and urge incontinence had similar impact. In addition, some of the QOL instruments used in this research (most notably the SF-12 summary scores) may not be sufficiently sensitive to detect true differences in QOL impact of UI by type or severity. ${ }^{24}$ Finally, the number of women with stress and urge incontinence in this study limits the power of our conclusions with respect to this subanalysis.

Whereas UI and FI both had a negative impact on SF-12 mental summary score and selfrated health utility index scores, our results suggest that dual incontinence had a greater negative impact than either FI or UI alone. These 2 conditions were often coincident in this population: $52.7 \%$ of the women with FI also had UI. This limited our ability to assess the independent influence of FI and UI on QOL. However, these conditions are commonly coincident in clinical practice. ${ }^{25}$ We found that women who reported both FI and UI had the worst QOL scores, including a negative impact on sexual function.

The magnitude of the impact of FI and UI on QOL can be compared with the impact of other chronic medical conditions. Specifically, we observed a 2.8-point difference in the SF-12 mental summary score for women with FI, compared with those without incontinence of stool or flatus. A similar decrease in the SF-12 mental summary score has been reported for hip impairment, rheumatoid arthritis, and kidney disease. ${ }^{26}$ This comparison provides a context for the magnitude of the observed impact on mental health.

In summary, both FI and UI symptoms were associated with decreased rating of overall health as well as a substantial negative impact on other dimensions of QOL. Because effective therapies are available for both FI and UI, clinicians who care for postpartum women should routinely screen for FI and UI and offer evaluation and treatment to women with these symptoms.

\section{Acknowledgments}

The authors would like to gratefully acknowledge the assistance of Robert Park, MD, Chairman of the PFDN Steering Committee (2001-2006).

This work was supported in part by Grants U01 HD41249, U10 HD41268, U10 HD41248, U10 HD41250, U10 HD41261, U10 HD41263, U10 HD41269, and U10 HD41267 from the National Institute of Child Health and Human Development.

\section{Appendix}

The following Pelvic Floor Disorders Network Members participated in the CAPS trial:

\section{University of Alabama at Birmingham}

Holly E. Richter, PhD, MD, principal investigator 
Kathryn L. Burgio, PhD, coprincipal investigator

Patricia S. Goode, MD, coinvestigator

R. Edward Varner, MD, coinvestigator

Velria Willis, RN, BSN, research coordinator

\section{Baylor College of Medicine}

Paul M. Fine, MD, principal investigator

Rodney A. Appell, MD, coprincipal investigator

Peter K. Thompson, MD, coinvestigator

Peter M. Lotze, MD, coinvestigator

Naomi Frierson., research coordinator

\section{University of lowa}

Ingrid Nygaard, MD, principal investigator

Debra Brandt, RN, research coordinator

Denise Haury, RN research coordinator

Karl Kreder, MD, coinvestigator

Catherine Bradley, MD, coinvestigator

Satish Rao, MD, coinvestigator

\section{Johns Hopkins Medical Institutions}

Geoffrey Cundiff, MD, principal investigator

Victoria Handa, MD, coinvestigator

Robert Gutman, MD, coinvestigator

Mary Elizabeth Sauter, NP, research coordinator

Jamie Wright, MD, coinvestigator

\section{Loyola University (Chicago, IL)}

Linda Brubaker, MD, principal investigator

Mary Pat Fitzgerald, MD, coprincipal investigator

Kimberly Kenton, MD, coinvestigator

Dorothea Koch, RN, research coordinator

Charity Ball, RN, research coordinator 


\section{University of North Carolina at Chapel Hill}

Anthony G. Visco, MD, principal investigator

AnnaMarie Connolly, MD, coinvestigator

John Lavelle, MD, coinvestigator

Mary J. Loomis, RN, research coordinator

Anita K. Murphy, NP, research coordinator

Ellen C. Wells, MD, coinvestigator

William E. Whitehead, PhD, coinvestigator

\section{University of Pittsburgh/Magee-Womens Hospitals}

Halina Zyczynski, MD, principal investigator

Diane Borello-France, $\mathrm{PhD}$, coinvestigator

Judy A. Gruss, MS, BS, research coordinator

Wendy Leng, MD, coinvestigator

Pamela A. Moalli, MD, PhD, coinvestigator

Elizabeth Sagan, MD, coinvestigator

Arnold Wald, MD, coinvestigator

\section{Data Coordinating Center: University of Michigan}

Morton B. Brown, $\mathrm{PhD}$, principal investigator

John T. Wei, MD, MS, coprincipal investigator

Beverly Marchant, RN, project manager

John O.L. DeLancey, MD, coinvestigator

Nancy K. Janz, PhD, coinvestigator

Dean G. Smith, PhD, coinvestigator

Patricia A. Wren, $\mathrm{PhD}$, coinvestigator

James Imus, MS, statistician

Yang Wang Casher, MS, database programmer

\section{Steering Committee Chairman}

Robert Park, MD 


\title{
National Institutes of Health Project Scientist
}

\author{
Anne M. Weber, MD, MS
}

\section{References}

1. Burgio KL, Zyczynski H, Locher JL, Richter HE, Redden DT, Wright KC. Urinary incontinence in the 12-month postpartum period. Obstet Gynecol. 2003; 102:1291-8. [PubMed: 14662217]

2. Fenner DE, Genberg B, Brahma P, Marek L, DeLancey JO. Fecal and urinary incontinence after vaginal delivery with anal sphincter disruption in an obstetrics unit in the United States. Am J Obstet Gynecol. 2003; 189:1543-9. discussion 1549-50. [PubMed: 14710059]

3. Hatem M, Fraser W, Lepire E. Postpartum urinary and anal incontinence: a population-based study of quality of life of primiparous women in Quebec. J Obstet Gynaecol Can. 2005; 27:682-8. [PubMed: 16100623]

4. van Brummen HJ, Bruinse HW, van de Pol G, Heintz AP, van der Vaart CH. Bothersome lower urinary tract symptoms 1 year after first delivery: prevalence and the effect of childbirth. BJU Int. 2006; 98:89-95. [PubMed: 16831150]

5. Viktrup L, Lose G. The risk of stress incontinence 5 years after first delivery. Am J Obstet Gynecol. 2001; 185:82-7. [PubMed: 11483909]

6. Dolan LM, Walsh D, Hamilton S, Marshall K, Thompson K, Ashe RG. A study of quality of life in primigravidae with urinary incontinence. Int Urogynecol J Pelvic Floor Dysfunct. 2004; 15:160-4. [PubMed: 15167993]

7. Zetterstrom JP, Lopez A, Anzen B, Dolk A, Norman M, Mellgren A. Anal incontinence after vaginal delivery: a prospective study in primiparous women. Br J Obstet Gynaecol. 1999; 106:32430. [PubMed: 10426238]

8. Borello-France D, Burgio KL, Richter HE, et al. Fecal and urinary incontinence in primiparous women. Obstet Gynecol. 2006; 108:863-72. [PubMed: 17012447]

9. Bharucha AE, Zinsmeister AR, Locke GR, et al. Prevalence and burden of fecal incontinence: a population-based study in women. Gastroenterology. 2005; 129:42-9. [PubMed: 16012933]

10. Nelson R, Norton N, Cautley E, Furner S. Community-based prevalence of anal incontinence. JAMA 16. 1995; 274:559-61.

11. Rockwood TH, Church JM, Fleshman JW, et al. Patient and surgeon ranking of the severity of symptoms associated with fecal incontinence: the fecal incontinence severity index. Dis Colon Rectum. 1999; 42:1525-32. [PubMed: 10613469]

12. Diokno AC, Brock BM, Brown MB, Herzog AR. Prevalence of urinary incontinence and other urological symptoms in the noninstitutionalized elderly. J Urol. 1986; 136:1022-25. [PubMed: 3490584]

13. Sandvik H, Seim A, Vanvik A, Hunskaar S. A severity index for epidemiological surveys of female urinary incontinence: comparison with 48-hour pad-weighing tests. Neurourol Urodyn. 2000; 19:137-45. [PubMed: 10679830]

14. Ware J Jr, Kosinski M, Keller SD. A 12-Item Short-Form Health Survey: construction of scales and preliminary tests of reliability and validity. Med Care. 1996; 34:220-33. [PubMed: 8628042]

15. Furlong WJ, Feeny DH, Torrance GW, Barr RD. The Health Utilities Index (HUI) system for assessing health-related quality of life in clinical studies. Ann Med. 2001; 33:375-84. [PubMed: 11491197]

16. Kwon S, Visco AG, Fitzgerald MP, Ye W, Whitehead WE. Validity and reliability of the Modified Manchester Health Questionnaire in assessing patients with fecal incontinence. Dis Colon Rectum. 2005; 48:323-31. discussion 331-4. [PubMed: 15616750]

17. Bug GJ, Kiff ES, Hosker G. A new condition-specific health-related quality of life questionnaire for the assessment of women with anal incontinence. BJOG. 2001; 108:1057-67. [PubMed: $11702838]$

18. Rogers RG, Coates KW, Kammerer-Doak D, Khalsa S, Qualls C. A short form of the Pelvic Organ Prolapse/Urinary Incontinence Sexual Questionnaire (PISQ-12). Int Urogynecol J Pelvic Floor Dysfunct. 2003; 14:164-8. discussion 168. [PubMed: 12955337] 
19. Boreham MK, Richter HE, Kenton KS, et al. Anal incontinence in women presenting for gynecologic care: prevalence, risk factors, and impact upon quality of life. Am J Obstet Gynecol. 2005; 192:1637-42. [PubMed: 15902170]

20. Varma MG, Brown JS, Creasman JM, et al. Fecal incontinence in females older than aged 40 years: who is at risk? Dis Colon Rectum. 2006; 49:841-51. [PubMed: 16741640]

21. Hagglund D, Walker-Engstrom ML, Larsson G, Leppert J. Quality of life and seeking help in women with urinary incontinence. Acta Obstet Gynecol Scand. 2001; 80:1051-5. [PubMed: 11703207]

22. Hunskaar S, Vinsnes A. The quality of life in women with urinary incontinence as measured by the sickness impact profile. J Am Geriatr Soc. 1991; 39:378-82. [PubMed: 2010587]

23. Coyne KS, Zhou Z, Thompson C, Versi E. The impact on health-related quality of life of stress, urge and mixed urinary incontinence. BJU Int. 2003; 92:731-5. [PubMed: 14616456]

24. Oh SJ, Ku JH. Impact of stress urinary incontinence and overactive bladder on micturition patterns and health-related quality of life. Int Urogynecol J Pelvic Floor Dysfunct. 2007; 18:65-71. [PubMed: 16575487]

25. Jackson SL, Weber AM, Hull TL, Mitchinson AR, Walters MD. Fecal incontinence in women with urinary incontinence and pelvic organ prolapse. Obstet Gynecol. 1997; 89:423-7. [PubMed: 9052598]

26. Ware, J.; Kosinski, M.; Keller, SD. SF-12: how to score the SF-12 Physical and Mental Health Summary Scales. 2nd. Boston (MA): The Health Institute, New England Medical Center; 
TABLE 1

Quality of life by fecal and flatal incontinence status

\begin{tabular}{|c|c|c|c|c|}
\hline Quality of life measure & $\begin{array}{l}\text { No fecal or flatal } \\
\text { incontinence } \\
\quad(n=507)\end{array}$ & $\begin{array}{l}\text { Flatal incontinence } \\
\qquad(\mathrm{n}=161)\end{array}$ & $\begin{array}{l}\text { Fecal incontinence } \\
\qquad(\mathrm{n}=91)\end{array}$ & $P$ value, adjusted \\
\hline $\begin{array}{l}\text { SF-12 physical component summary score } \\
\text { (range } 0-100 \text { ) }\end{array}$ & $55.4 \pm 5.4$ & $55.3 \pm 5.9$ & $54.4 \pm 7.5$ & .05 \\
\hline $\begin{array}{l}\text { SF-12 mental component summary score (range } \\
0-100)\end{array}$ & $51.1 \pm 8.7$ & $49.4 \pm 7.9^{*}$ & $46.8 \pm 9.2^{\dagger}$ & $<.0001$ \\
\hline Health utility index (range 0-100) & $88.0 \pm 11.6$ & $85.5 \pm 8.8^{*}$ & $85.1 \pm 9.8^{*}$ & .02 \\
\hline Manchester impact item ${ }^{\neq}$ & $10(2.0 \%)$ & $12(7.5 \%)$ & $17(18.7 \%)^{*}$ & $<.0001$ \\
\hline Manchester severity score (range 0-100) & $1.0 \pm 5.2$ & $2.2 \pm 6.1^{*}$ & $11.3 \pm 17.0^{\dagger}$ & $<.0001$ \\
\hline Sexually active $\S$ & $305(83.1 \%)$ & $100(87.0 \%)$ & $54(80.6 \%)$ & .19 \\
\hline PISQ-12 score (range $0-48)^{\S}$ & $39.1 \pm 4.3$ & $38.1 \pm 4.2$ & $37.5 \pm 5.2$ & .09 \\
\hline
\end{tabular}

Groups are presented regardless of urinary incontinence status. Data presented as mean \pm SD or n (\%). $P$ values based on analysis of variance or Mantel-Haenszel statistic (adjusted for site, race, and marital status).

* Significantly different from "no FI," adjusted $P<.05$.

${ }^{\dagger}$ Significantly different from both of the other groups, adjusted $P<.05$.

*How much do you think your bowel problem affects your life?" Positive response = "moderately," "quite a bit," or "extremely."

$\S_{\text {Sexual function and PISQ-12 scores are presented for women enrolled after the PISQ-12 questionnaire was added to this protocol. }}$

Handa. The impact of fecal and urinary incontinence on quality of life. Am J Obstet Gynecol 2007. 
TABLE 2

Relationship between fecal and urinary incontinence 6 months after first delivery

\begin{tabular}{lllll}
\hline Urinary continence status & No FI $(\mathbf{n = 5 0 7})$ & Flatal incontinence only $(\mathbf{n}=\mathbf{1 6 1})$ & FI $(\mathbf{n}=91)$ & Total $(\mathbf{n}=\mathbf{7 5 9})$ \\
\hline SUI (only) & $65(12.8 \%)$ & $37(23.0 \%)$ & $19(20.9 \%)$ & 121 \\
\hline Urge or mixed incontinence & $64(12.6 \%)$ & $23(14.3 \%)$ & $29(31.9 \%)$ & 116 \\
\hline No UI (continent) & $378(74.6 \%)$ & $101(62.7 \%)$ & $43(47.3 \%)$ & 522 \\
\hline Total & 507 & 161 & 91 & 759 \\
\hline
\end{tabular}

Data presented as n (column \%). There is a significant association between FI and UI status $(P<.001)$.

SUI, stress urinary incontinence.

Handa. The impact of fecal and urinary incontinence on quality of life. Am J Obstet Gynecol 2007. 
